\title{
The Research of Undergraduate Engineering Education Based on the Students' Ability to Solve Complex Engineering Problems
}

\author{
Chen Shuying \\ Key Laboratory of Intelligent Information Processing in \\ Universities of Shandong \\ Shandong Institute of Business and Technology \\ Yan Tai, China \\ 304779566@qq.com
}

\author{
Chen Lei \\ Coal Economy Academy \\ Shandong Institute of Business and Technology \\ Yan Tai, China \\ chenl77@163.com
}

\begin{abstract}
Since the beginning of China's engineering education accreditation, especially after China's accession to the Washington Agreement, the ability to solve complex engineering problems has become the basic orientation of undergraduate engineering education. This paper analyzed the basic requirements of professional education from the definition of complex engineering problems, recovered that we must use deep engineering principles and system concept to solve them. This article discussed the teaching content selection from the theory and practice, the activities implementation and the evaluation standard. It gave the way to cultivate students' ability to solve complex engineering problems, and showed the process to promote the realization of international equivalence of our undergraduate engineering education. This paper makes a useful exploration to improve the students' ability to solve complex engineering problems in the undergraduate education of other subjects.
\end{abstract}

Keywords - engineering education; undergraduate engineering education; complex engineering problems; system concept; system capability

\section{INTRODUCTION}

The purpose of the Internet of things is to use network technology to integrate services. The concept of system development is the result of the integration of embedded technology and Internet. The "system" is ubiquity. The state of things can be perceived, measured and monitored. Intelligent systems make it easier to predict events. The allocation is more optimized. Embedded technology brings new challenges to the ability training of the system. Computer technology is a public technology, other non computer professional students are also learning the computer technology, and then what is the advantage of computer science students? Our students of computer science must have the system development concept, they can understand the computer including computer hardware and software, and they can grasp the relationship between each other with the concept of the system. We have to reform the course content and teaching methods, otherwise we have no competitive advantage. We should focus on how to improve the system ability of the students of computer science

It is sponsored by National Natural Science Foundation of China (No (61272244, 61672327)) The Natural Science Foundation of Shandong Province of China (No. (ZR2014FL007))

The High Level Application Oriented Key Project Construction Specialties of Shandong Province of China

Applied Talents Training Professional Development Support Program in colleges of Shandong Province of China (No. (5001-015-34401))

Research on Teaching Reform of Undergraduate Colleges and Universities of Shandong Province in 2016 and technology. The key content of system development and system capability is how to build a computer application system on the basis of mastering the basic principles of computer. The curriculum system and content construction of computer major students should keep pace with the times, constantly renovate and bring forth new ideas. For most computer undergraduate students, their ability of hardware design are poor than that of the electronic engineering industry, their software development and application ability can not keep up with the other related majors, their mathematical theory are less than the mathematics students. The ability of computer system is the specialty of computer majors. How to improve the ability of computer major students is a problem we must solve. As the same time, it is very important to improve continuously the quality of education in the pursuit of higher education. Especially the higher education of our country transformed from elite education to mass education in a relatively short period, now it is currently in the process of transforming from extensive development based on scale expansion to connotative development based on quality improvement.

In 2006, China took part in in engineering education accreditation [1], it takes the international standards of engineering education as a breakthrough, to improve the quality by strengthening the connotation development. The accreditation plays an important role in leading and demonstration, especially in promoting the renewal of education concept, establishing the standard consciousness and strengthening the quality consciousness. It has been proved by the practice of ten years. China formally joined the "Washington Agreement" (hereinafter referred to as the "agreement") on June 2, 2016, it is considered to be the historic breakthrough of higher education [2]. In the future, we need to increase the intensity to promote the undergraduate engineering education in higher education institutions to meet the accreditation standards of engineering education (hereinafter referred to as the standard) in China, promote comprehensively the undergraduate engineering education in China to achieve the international equivalent of the meaning of the agreement, as 
the meanwhile it can provide reference for other professional categories of education.

The students of computer science are not fully aware of the concept of computer system development, and even lack of such a system development concept, the students can not link the key points between each course. They study each course dispersedly, but do not know the intrinsic link between the curriculums. They do not have the concept of system development and system capabilities, can not solve complex engineering problems. They are also lack of systematic and comprehensive practice, which makes students have a smattering of knowledge and practical ability.

Generally speaking, the current computer professional teaching in colleges and universities in China paid less attention to the training.

- It lacks an independent course in the whole computer system.

- The computer professional courses are not closely linked to each other.

- The specific content of the course of computer science is not keeping pace with the times, that is, the content of the course is relatively backward and not keeping up with the current development of computer technology.

- Lack of overall consideration of system design and application ability training in the curriculum system.

\section{THE BASIC ORIENTATION OF UNDERGRADUATE ENGINEERING EDUCATION IS TO CULTIVATE STUDENTS' ABILITY TO SOLVE \\ COMPLEX ENGINEERING PROBLEMS.}

The agreement advocated student-centered, outcome based education and continue quality improvement three education ideas, it requires systematic design and implementation from the training objectives to the graduation requirements, the curriculum system, teaching implementation, evaluation and feedback. The training target is a beginning, it needs to run education from the discipline oriented education (elite education) to the society oriented education (mass education).The social demand determines the training objectives. Of course, training objectives must meet the basic orientation of education as a basic requirement. In accordance with the agreement, the two-year college students should solve well-defined problems, three-year college students should solve the broadly-defined problems, undergraduate students should solve the complex engineering problems.

The complex engineering problems have the following characteristics [3]:

- It is necessary to apply the deep engineering principles to solve the problem;

- Requirements involve a wide range of technical, engineering and other factors, and may conflict with each other;
- It is necessary to establish a suitable abstract model to solve the problem, it needs to reflect the creativity in the modeling process;

- It can not be completely solved by common methods;

- The factors involved in the problem may not be fully included in the professional standards and norms;

- The interests of the parties concerned are not entirely consistent;

- It has a high degree of integration, including a number of interrelated sub problems.

The first of these is essential. It points out the nature of complex engineering problems; the second to seventh is optional and can be seen as a representation of complex engineering problems.

Equivalent to the agreement, the graduation requirements of the undergraduate students should also reflect this basic position. It is necessary to put the practical ability on the basis of basic principle, it is that the practice should follow the guidance of theory, the theory should combine with practice.

\section{THE BASIC REQUIREMENTS OF PROFESSIONAL EDUCATION FOR SOLVING COMPLEX ENGINEERING PROBLEMS}

In order to cultivate students' ability to solve complex engineering problems, this paper puts forward specific requirements for undergraduate engineering education. The following characteristics of complex engineering problems are discussed in turn

- The undergraduate students must use deep engineering principles to solve complex engineering problems. On the whole, there is no fixed rules, simple repetition, or methods to solve this problem, it needs be analyzed (not directly applied) based on a deep (rather than simple) basic principle, then can be solved. This clearly put forward the future oriented undergraduate education and innovation oriented basic pursuit from another point of view, it also rejected those who thinks he has learned a lot of knowledge but lacks practical ability, The way that use vocational training instead of undergraduate education practice is inappropriate, we should learn in order to practice.

- First of all, the curriculum system and curriculum content need to include the basic content of the subject, as well as related fields and disciplines. We should encourage students to select courses cross profession and avoid limiting in a very narrow direction and technology. Secondly, the corresponding teaching content should include multiple factors and technology, we can discuss the pros and cons of the content, let the students know how to learn and choose, they should consider the problem from the overall perspective.

- We should cultivate the students' ability to understand the abstract models. They should be able to choose abstract models based on actual needs . The abstract model is constructed by using the abstract model to 
represent the problem (the state and the change rules of the system), the engineering practice is based on the abstract model. The students obtain the basic knowledge, basic model, basic ideas and methods from mathematics and the natural sciences, they learn the typical model, ideas and methods from the basic courses in disciplines and the professional knowledge related to professional courses. The students experience deeply and practice in curriculum design, graduation design practice and the exercises of the theoretical courses. A basic aim is that the students can understand the model, choose the different models and construct the models, even they can do model calculation and engineering implementation.

- Common methods can not completely solve the complex engineering problems, it needs to be integrated, new ways should be found. Of course, this new method is inspired by existing methods, it also can be integrated of multiple methods. This reflects the students' comprehensive ability and the capacity of developing tools. As far as the experiment is concerned, it is necessary to start from the verification experiment, emphasize the comprehensive experiment and design experiment. We allow students to learn gradually how to solve the problem on the basis of the principle and the method. Of course, this kind of education needs to be linked cooperative arrangements such as designing more comprehensive problems in the exercise.

- Although the factors involved in the problem may not be fully included in the professional standards and norms, the problem solving is consistent with the basic principles. The students are required to use what they have learned to solve the problem according to the engineering situation, while considering the related society, environment, ethics, morality and other aspects of the project.

- The interests of all parties are inconsistent, we should do well in the interests of the balance and compromise, so that it can be local optimization and global optimization, locality obeys to the overall situation [4].

- We emphasize the cultivation of students' systematic perspective, so that the students can stand at the systematic level to see the problem with the systematic perspective, the students are able to deal with the complex problems and solve them, they will not fall into locality or ignore the problem space only for some specific phenomena.

From the above we can see that the students need to use flexibly what they have learned to solve the complex engineering problems. The cultivation of innovation consciousness and innovation ability must be carried out in the first class. The idea that the innovation is too high to be reached is wrong, we can not repose the hope in the second classes and the simple activities of science and technology.

\section{THE TRAINING OF THE ABILITY TO SOLVE COMPLEX ENGINEERING PROBLEMS}

It must be achieved through the training system to cultivate students' ability of solving complex engineering problems, it should be decomposed into every aspect of culture. It is important to point out that the complex engineering problem and the ability to solve complex engineering problems are two different concepts, we can not take the ability to solve complex engineering problems as the participation of a complex project in a narrow sense, or even rely on the graduation design, comprehensive practice thoroughly [5]

- Arrange the content of theoretical courses in accordance with the graduation requirements of solving the complex engineering problems. The curriculum content must include deep engineering principle in relevant fields, it is not just the simple content, it includes the basic complete content, more than simply know and calculation, it must reach a certain depth. More importantly, the curriculum content also includes the corresponding ideas and methods, especially the ideas and methods used repeated in the students career. These contents must be given a specific description in the syllabus of the course, which is not satisfied with the requirements. In the syllabus, the teaching objectives of the course must be corresponding to the graduation requirements, in order to put the curriculum in the whole training system.

The theoretical teaching activities should be carried out in accordance with the need of meeting the complex engineering problem graduation requirements.

- The course teaching should be implemented following the syllabus so that the students can master the basic principle deeply, understand its essence, grasp the ideas and methods, the students should combine the basic principle with the engineering practice organically, explore the application of the method and experience the fun.

- According to the need to solve the complex engineering problems, the theoretical teaching should be evaluated. The results were evaluated by means of examination, reply, report and acceptance.

The value of teaching activities is reflected in the support of the graduation requirements. So we determine the evaluation method, title and observation points according to the graduation requirements of the course, ensure that the evaluation can effectively reflect its commitment to the graduation requirements. Ensure that the assessment of the content, methods, and scoring system can fully reflect the needs of the corresponding requirements for graduation achievement degree.

Output oriented requirements focus on the ability to solve complex engineering problems, the examination must get rid of the inclination of subjective questions, avoid the simple pursuit of the pass rate tendency, we should assess according to the syllabus of the teaching objectives. 
- Arrange the practice teaching content in accordance with the need to solve the complex engineering problems graduation requirements.

First of all, the practice teaching must choose the appropriate carrier, to enable students to experience the complex engineering construction (system), and reflect the comprehensive application of the knowledge, technology and the method in the process of building [6]. Secondly, it should form a sequential progressive system from simple to complex, from small to large. It is also necessary for the students to experience the major professional practice as fully as possible. Finally, the students complete the task of graduation from the selection of topics and the arrangement of the specific content according to the requirements of the curriculum, the pursuit of the practice should be under the guidance of theory; the practice includes the design, the implementation and the analysis (system analysis, analysis of results); it is able to effectively promote the students to master the principle of engineering further, it is combined with the engineering practice in order to avoid simply practice; we can create opportunities for students, so that they can get more comprehensive exercise.

- We need to carry out the practical teaching activities to meet the needs of the graduation project. We should be strict with the students and give them proper guidance. In the concrete teaching, we must urge the students to study the analysis of the problems and the research of related content (data), guide the students to gather the related material and the information to study new technology. We should help them to master the experimental technique and the method. We should implement the design and implementation, cooperating with the people, things and the system of multi collaborative work [7]. We should learn to evaluate the work and the system; study the influence of project development to the society, the environment, the law, the ethics, and the moral norm, develop our social responsibility. We should guide the students to consider the problems and its solutions, methods, ways, tools. We should teach students to experience the beauty of the principle in the practical case of the combination of basic principles and engineering practice. In order to obtain a better practice effect, we should achieve the combination of curricular class and extracurricular activity.

- Carry out the practical teaching evaluation in accordance with the needs to solve the complex engineering problems graduation requirements.

The teaching effect should be evaluated in accordance with the provisions of the syllabus, the corresponding assessment methods and scoring standards can truly reflect the teaching activities to support the actual contribution to the graduation requirements.

\section{DEVELOP SYSTEM CONCEPT AND IMPROVE SYSTEM CAPABILITY}

We should start from the concept of the system, to develop students' ability to understand the system, system design, system development and system application of these four areas. The teaching methods of computer science and technology should pay attention to train students to think and solve problems from the angle of system [8]. We need to have a thorough understanding of the basic principles of hardware and software in computer science. As the same time, we should pay attention to train the students to have system concept in the process of the experiment. We should consciously develop the students' ability to understand, design, develop and apply the system concept. So that students can stand on the height of the system to consider and solve problems, and be able to develop a system of software hardware through talent.

\section{CONCLUSION}

Undergraduate education should face the future problem solution and the future development of the students, the quality of the students is ultimately reflected on the future development of society. It is important to clarify the basic requirements of training students' ability of solving complex engineering problems. We should grasp its meaning, and decompose them into all aspects of personnel training in the implementation. At the same time, as a reference, other categories of undergraduate education should focus on the cultivation of the ability to solve complex problems, so that it can promote rapidly and improve the quality and level of undergraduate education, in order to meet the needs of society and its development.

\section{REFERENCES}

[1] Graduate Attributes and Professional Computencies ,http://www.ieagreement.org.

[2] Peng Pai, "Evaluation and International Comparison of Learning Outcomes of Engineering Education", Higher Engineering Education Research:PP. 18-38, May 2016(In Chinese).

[3] Liu Weidong,zhang Youhui, "The Construction of the Curriculum System of Computer Specialty Oriented to the Development of System Ability" , Chinese University Teaching,vol. 8, pp. 48-52, August 2014(In Chinese)

[4] Lin Jian, "Method of Understanding and Solving Complex Engineering Problems", Higher Engineering Education Research: pp.17-38,May 2016(In Chinese)

[5] Wang Zhiying,Zhou Xingshe,Yuan Chunfeng,Wu Gongyi,Zhang Gang,He Yanxiang,Chen Xiangqun, "Research on the Cultivation of Students' Ability of Computer Science and the Establishment of Systematic Curriculum System," Computer Education: pp. 1-6,June 2013(In Chinese)

[6] Luo Xianlu,Tan Deli, Zhang Yongtang,Chen Guihong, "The Application-oriented Undergraduate Computer Class Corse Systsem Based on System Ability Training," Software Engineering, Vol 19: pp. 55-57,February 2016(In Chinese).

[7] MIT.Computation Structures,Spring 2013.Http://6004.mit.edu/

[8] Kumar,P.,Singh,Y..An Empirical Study of Software Reliability Prediction Using Machine Learning Techniques.Int.J.Syst.Assur.Eng.Manag,pp.194-208,March2012 